\title{
Studies on the Transport of Aromatic Solvents through Filled Natural Rubber
}

\author{
Isaac O. Igwe and Obumneme E. Ezeani \\ Department of Polymer and Textile Engineering, Federal University of Technology, Owerri, P.M.B 1526, Owerri, Nigeria \\ Correspondence should be addressed to Isaac O. Igwe, izikigwe@yahoo.com
}

Received 5 July 2011; Accepted 25 October 2011

Academic Editor: Avraam I. Isayev

Copyright (๑) 2012 I. O. Igwe and O. E. Ezeani. This is an open access article distributed under the Creative Commons Attribution License, which permits unrestricted use, distribution, and reproduction in any medium, provided the original work is properly cited.

The transport of three aromatic solvents (benzene, toluene and xylene) through snail shell powder filled natural rubber was studied at 313,333 , and $353 \mathrm{~K}$ by conventional weight-gain experiments. The effects of snail shell powder content, particle size, nature of solvent, and temperature on the transport characteristics of natural rubber were determined. The estimated Arrhenius activation energies for the processes of sorption, diffusion, and permeation showed that the activation energies were highest in xylene at all the filler contents investigated. The calculated enthalpies, and entropies of sorption were all positive for the solvents investigated. Similarly, the change in the estimated free energies of sorption were all positive; an indication of the non-spontaneity of the solubility of snail shell powder filled natural rubber in the aromatic solvents at $313 \mathrm{k}$.

\section{Introduction}

Natural rubbers are widely used in the transportation, consumer, industrial, hygiene, and medical sectors where they provide decorative finish, high resilience, high tear strength, and so forth. Towards the end of the last century, great attention has been focused on the diffusion, sorption, and permeation of solvents into elastomers since these basic phenomena play vital roles in several important areas of engineering and industry. Thus, in the design and fabrication of barrier rubber materials for the transportation of liquids and gases, packaging of food stuffs, and so forth, it is of considerable importance to carry out transport studies so as to eliminate the diffusion of chemicals into such reinforced natural rubber products. This is necessary because the presence of these chemicals may affect the mechanical performance of the rubber material, degrade the product that the reinforced natural rubber is to protect, damage the interface between the rubber and another material, or even pollute the environment (e.g., diffusion leakage from storage vessels). Thus, it is necessary to understand the sorption, diffusion, and permeation processes in natural rubbers since this is critical to the development of reliable reinforced natural rubber products for use in the demanding environment.
Therefore, the transport behaviour of various organic solvents through different polymers and rubbers is of great technological importance since it plays a vital role in a variety of barrier applications [1-3]. The transports of solvents through polymer systems have received adequate attention in the scientific literature, and are reviewed below.

The solubility, diffusivity, and permeability of ethylbenzene in poly[1-trimethylsilyl-1-propyne] (PTMSP) were studied by Dixon-Garrett et al. [4]. They found that the diffusion coefficient of ethylbenzene in PTMSP decreased with increased concentration of ethylbenzene and decreased temperature of study.

The rate of absorption of benzene by open cell polyurethane foam of various sizes was studied by Sefton and Mann [5]. The rate of absorption was found to depend on the size of the foam. Experimental results obtained suggested that bulk flow was more rapid than pore diffusion, and it was concluded that pore diffusion was more important than bulk flow in foams.

Similarly, Schneider et al. [6] investigated the sorption and diffusion of a series of liquids through polyurethane membrane. The sorption experiments in n-heptane and incremental sorption experiments in $n$-heptane vapour were found to be Fickian. With increasing polarity of liquids, 
the swelling behaviour of the liquids was found to increase to a maximum level.

Aminabhavi and Aithal [2] studied the interactions of industrially important solvents with commercially available polyurethane. With the exception of trichloromethylene, sorption was found to increase with increase in temperature. This was attributed to the specific interaction of trichloroethylene with the hard segment part of polyurethane. The diffusivity and permeability values were found to be higher for trichloroethylene and 1,2-dichloroethylene when compared to other penetrants studied.

The diffusion characteristics of aromatic solvents into polypropylene, and polyethylene films have been reported in the literature $[7,8]$. The diffusivity and permeability of the solvents into polypropylene films increased in the order of solvents, benzene, toluene, and xylene at the temperatures of investigation. The above properties were also found to be temperature dependent. Similarly, the permeability, solubility, and diffusivity of the aromatic solvents in polyethylene were found to increase with increase in temperature, and the calculated enthalpies of sorption for the solvents in polyethylene were positive while the calculated entropies of sorption were negative.

The study of diffusion, sorption, and permeation in polymer blend structures provides a valuable means for additional characterization of polymer blends. The diffusion behaviour in polymer blends was first reported by Cates and White [9-11] who investigated the water sorption characteristics of polyacrylonitrile (PAN)/cellulose, PAN/silk, and PAN/cellulose acetate blends. The diffusion behaviour of polyethylene-polystyrene (PE-PS) semi-interpenetrating polymer networks (IPNs) in toluene and chloroform was investigated by Hong and Duda [12]. In the blend of PE and nylon 6, it was found that the permeability to heptane, methyl salicylate, and methyl alcohol varied with blend ratio.

The diffusion characteristics of toluene, an aromatic solvent into natural rubber/linear low-density polyethylene blends were investigated by Obasi et al. [13]. The transport of toluene through most of the blend compositions was anomalous, although at $55^{\circ} \mathrm{C}$, the transport of toluene through the 60/40 NR/LLDPE blend was Fickian, and at $35^{\circ} \mathrm{C}$, pseudoFickian. The diffusion coefficient and permeability to toluene in 50/50 and 60/40 NR/LLDPE blends were found to increase with increase in sorption temperature.

The diffusivity in a given polymer system, whether it is rubbery polymers, glassy polymers, polymer blend, graft, or interpenetrating polymer networks, varies from one polymer system to another $[14,15]$. Diffusivity depends on the free volume within the material and the segmental mobility of polymer chains, crosslinking of component polymer phases, size of penetrants, and so forth $[16,17]$.

The effect of fillers on the transport characteristics of polymers has been of immense interest to scientists, and reports on the effect of fillers on the diffusion and sorption processes exist [18-21]. Thus, Kwei and Kunins [22] found that the sorption of chloroform by an epoxy resin was lowered by about $70 \%$ when $5 \%$ filler was incorporated. Similarly, Boonstra and Dannenberg [23] presented the equilibrium swelling data of filled natural rubber and a number of synthetic rubbers in a variety of solvents. They observed that fillers like carbon black caused a reduction in swelling of the membranes, and which was commensurate with the volume loading of the filler. However, the effect they observed was not specific on a particular solvent or elastomer. The noncarbon black filler caused a reduction in rubber swelling, which was not dependent on the filler content.

Stickney and Mueller [24] studied the kinetics of swelling of carbon black-filled styrene-butadiene rubber vulcanizates in isooctane. It was found that, for rubber vulcanizates, diffusivity increased with the concentration of the penetrant.

Lawandy and Helaly [25] investigated the diffusion of chloroform in neoprene rubber vulcanizates containing different types of carbon black and reported that the penetration rate decreased with increase in the particle size of carbon black. Similarly, a decrease in penetration rate at high degree of equilibrium volume swelling was found. These results were attributed to the winkles formed at the surface of the rubber at high equilibrium swelling.

Ahmad et al. [26] investigated the swelling properties of filled natural rubber/linear low-density polyethylene blends in toluene for $24 \mathrm{~h}$. It was found that the swelling index decreased with increase in filler loading, and this was attributed to increases in the cross-link density.

In the present study, we report the studies on the transport of aromatic solvents (benzene, toluene, and xylene) through snail shell powder filled natural rubber at 313, 333, and $353 \mathrm{~K}$. This work is an extension of our investigations on the use of snail shell powder as a filler for natural rubber. The use of snail shell powder as a filler in compounding natural rubber was first reported by Igwe and Ejim [27].

The transport of liquids through snail shell powder filled natural rubber has not been reported in the scientific literature to our knowledge. The central objectives of the present study are as follows.

(i) Investigate the effects of snail shell powder filler content and particle size on the transport of benzene, toluene, and xylene through vulcanized natural rubber.

(ii) Investigate the effects of temperature on the transport of aromatic solvents through the filled natural rubber.

(iii) Determine the effects of solvent properties on the transport process in vulcanized natural rubber.

(iv) Determine the mechanism of sorption of the aromatic solvents investigated through snail shell powder filled natural rubber.

\section{Experimental}

2.1. Materials Used. The snail shell powder filled natural rubber vulcanizates used in this study were compounded at Dunlop Plc, Lagos, Nigeria. The snail shell was obtained locally, processed, and sieved to 0.075 and $0.30 \mu \mathrm{m}$ mesh sizes, respectively. The following weights $(\mathrm{g})$ of snail shell powder were used in compounding the natural rubber: 2 , $5,10,15$, and 20 . The rubber vulcanizates are in form of rectangular sheets measuring $7.40 \times 23.10 \mathrm{~cm}$, with 
TABle 1: Properties of solvents.

\begin{tabular}{lcccc}
\hline Solvent & Density $\left(\mathrm{g} / \mathrm{cm}^{3}\right)$ & $\begin{array}{c}\text { Molecular mass volume } \\
\left(M_{v}\right),(\mathrm{g} / \mathrm{mol})\end{array}$ & Dipole moment $(D)$ & $\begin{array}{c}\text { Solubility parameter } \\
(\mathrm{Mpa})^{1 / 2}\end{array}$ \\
\hline Benzene & 0.879 & 78.12 & 0 & 18.7 \\
Toluene & 0.866 & 92.14 & 0.36 & 18.3 \\
Xylene & 0.865 & 106.17 & 0.70 & 18.2 \\
\hline
\end{tabular}

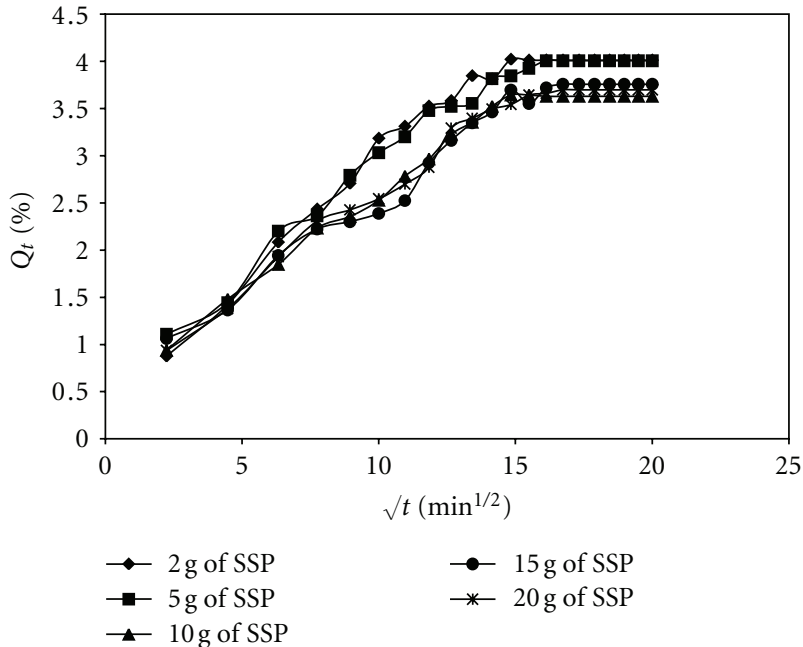

Figure 1: Plot of $\% Q_{t}$ versus $\sqrt{t}\left(\min ^{1 / 2}\right)$ for snail shell powder (particle size, $0.075 \mu \mathrm{m}$ ) filled natural rubber in benzene at different filler content at $313 \mathrm{~K}$.

approximate thickness, $0.35 \mathrm{~cm}$. The solvents used in this study are analytical-grade benzene, toluene, and xylene and were used without further purifications. The properties of the solvents used are presented in Table 1 . The procedure for the sorption experiment was as described previously $[7,8]$, except that in this study, the following temperatures were investigated: 313,333 , and $353 \mathrm{~K}$. An approximately $0.175 \mathrm{~g}$ of the snail shell powder filled natural rubber was used for the sorption experiment.

\section{Results and Discussion}

The uptake of the aromatic solvents (benzene, toluene, and xylene) by snail shell powder-filled natural rubber vulcanizates have been investigated using the conventional weightgain method. The sorption behaviour of the rubber vulcanizates, prepared in two different particle sizes of snail shell powder, namely, 0.075 , and $0.300 \mu \mathrm{m}$, were studied at the following temperatures 313,333 , and $353 \mathrm{~K}$. The sorption data obtained for the filled natural rubber at the temperatures investigated were expressed as the molar percentage uptake $\left(\% Q_{t}\right)$ of the solvents per gram of the rubber vulcanizate. $\% Q_{t}$ was calculated using the following equation [28]:

$\% Q_{t}=$ (Mass of solvent absorbed/Molecular weight of solvent/Initial mass of the rubber vulcanizate $) \times 100$.

The molar percentage uptake $\left(\% Q_{t}\right)$ at any particular temperature and snail shell powder particle size were plotted against the square root of time $(\sqrt{t})$ as illustrated in Figures $1,2,3$, and 4 . Each of these figures shows initial increases in the mass of the solvent sorbed, until maximum absorption was reached, at which time, the mass of the absorbed solvent remained constant, that is, equilibrium absorption was attained.

The higher initial solvent absorption rates in polymers have been explained in terms of rapid cavitations, which expose a greater surface area, thus enhancing solvent percolation [29]. On the other hand, at equilibrium, the solvent uptake is counter balanced by solvent extraction from the polymer. Obasi et al. [13] who investigated the transport of toluene through linear low-density polyethylene/natural rubber blends also found that the mass of toluene sorbed generally increased with time at the temperatures investigated until the maximum absorption was reached, at which time, the mass of toluene sorbed remained constant. Similar observation had been noted for other polymer systems [16, $28,30,31]$.

The figures show that solvent uptake for any particular solvent at the filler particle sizes used $(0.075$ and $0.30 \mu \mathrm{m})$ generally increased with increase in sorption temperature. This occurs because the diffusing solvent molecule is facilitated by the higher thermal energies at increased temperature. This results in a subsequent reduction in the viscosity of the solvents, and a further increase in the segmental mobility of the polymers. The increase in the mass of solvent sorbed by polymers with increase in temperature had been reported in the scientific literature. For example, Johnson and Thomas [30] who studied the effect of epoxidation on the transport behavior and mechanical properties of natural rubber reported that the mole percentage uptake of hexane in epoxidized rubber (ENR-50) showed increases with increase in temperature. 


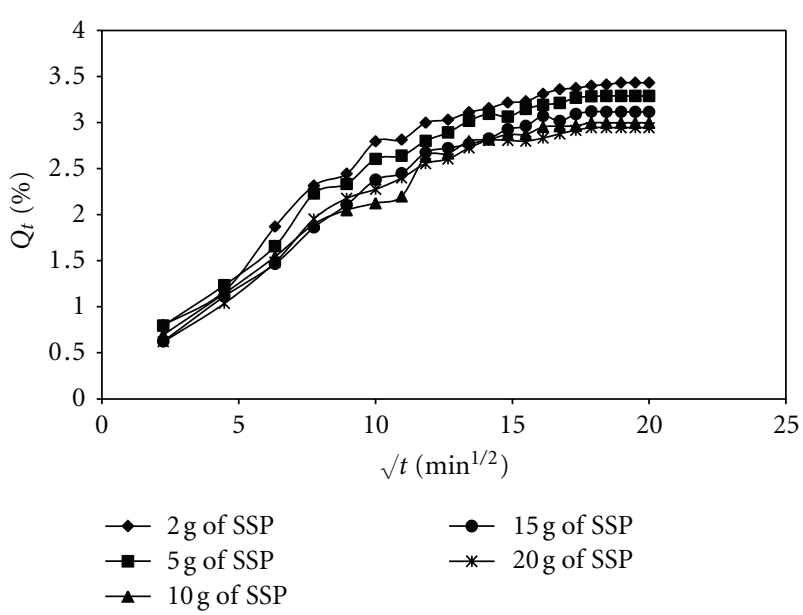

Figure 2: Plot of $\% Q_{t}$ versus $\sqrt{t}\left(\mathrm{~min}^{1 / 2}\right)$ for snail shell powder (particle size, $0.075 \mu \mathrm{m}$ ) filled natural rubber in xylene at different filler content at $333 \mathrm{~K}$.

\section{Analysis of the Sorption Data}

4.1. The Diffusion Coefficient (D). The kinetic parameter, the diffusion coefficient $(D)$, for the different filled natural rubber- (NR-) penetrant systems was calculated [2]:

$$
D=\Pi\left(\frac{h \theta}{4 Q_{\infty}}\right)^{2},
$$

where $h$ is the initial sample thickness, $\theta$ is the slope of the linear portion of the sorption curve of the plot of $\% Q_{t}$ versus $\sqrt{t}$, and $Q_{\infty}$ is the equilibrium absorption. The values of $D$ for the different rubber systems are given in Table 2 . Table 2 shows that $D$ values generally increase with increase in the molecular mass of the solvent used, where the order in the molecular weight of the solvents is xylene $>$ toluene $>$ benzene. This order is also in the direction of increasing molecular mass volume, and dipole moment, and decreasing density and solubility parameter of the solvents as shown in Table 1. The higher diffusion coefficient observed for xylene could be due to the closeness of its solubility parameter (18.2 Mpa) to that of natural rubber (16.2 Mpa). The solubility parameter, which is a measure of intermolecular attraction, is a very important factor that affects solubility of polymers in solvents. Thus, polymers and solvents soften or dissolve if they have similar solubility parameter values. In other words, the present study has shown a dependence of diffusivity on the molecular mass of solvents. This is in contrast to the findings of some authors [30, 32] who reported an inverse dependence of $D$ on the molecular weight of solvents. An increase in the diffusion coefficient of some polymers with increases in the molecular mass of penetrant molecules has been reported in the literature $[7,8]$. It is important to note that diffusivity in a given polymer system, whether it is rubbery or glassy polymers, polymer blends, graft, or interpenetrating polymer networks as pointed out earlier varies from one polymer system to another.

Table 2 also shows that the $D$ values generally decrease with increase in sorption temperature for any particular

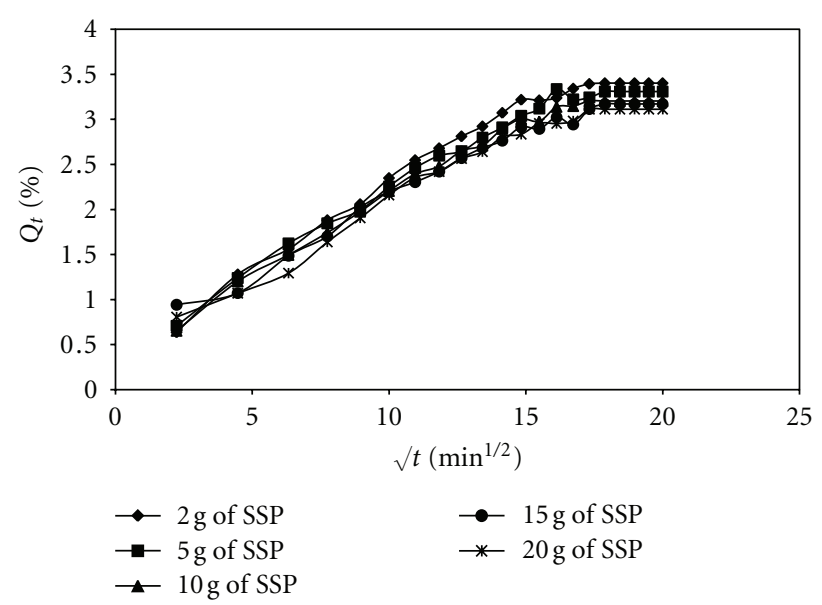

Figure 3: Plot of $\% Q_{t}$ versus $\sqrt{t}\left(\min ^{1 / 2}\right)$ for snail shell powder (particle size, $0.300 \mu \mathrm{m}$ ) filled natural rubber in toluene at different filler content at $313 \mathrm{~K}$.

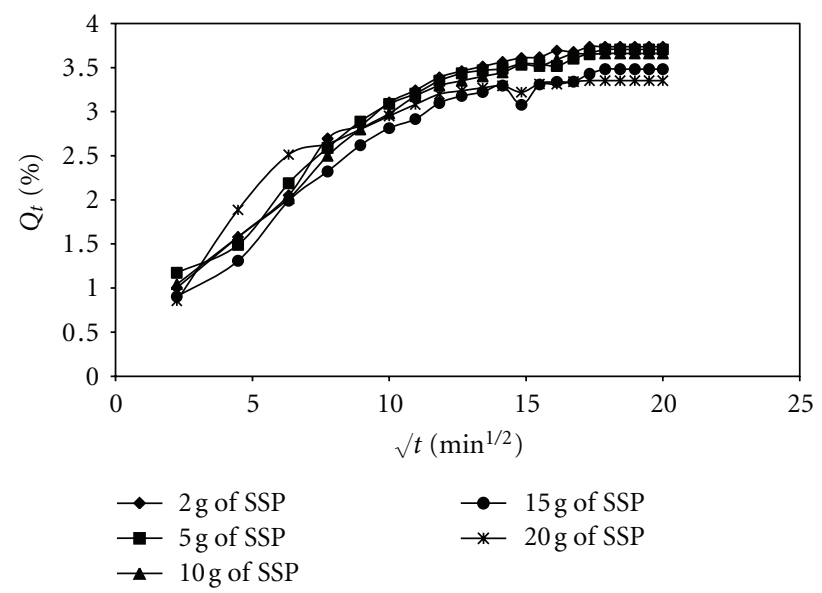

Figure 4: Plot of $\% Q_{t}$ versus $\sqrt{t}\left(\min ^{1 / 2}\right)$ for snail shell powder (particle size, $0.300 \mu \mathrm{m}$ ) filled natural rubber in toluene at different filler content at $353 \mathrm{~K}$.

solvent and filler particle size considered. The temperature effect may be because the diffusing molecules are defacilitated by the higher thermal energies at the increased temperature. However, Johnson and Thomas [30] had reported an increase in the diffusion coefficient $(D)$ with increase in sorption temperature.

Table 2 also shows that there was no strong dependence of $D$ on filler content at any temperature of investigation considered. However, Stickney and Muller [24] who studied the swelling of carbon black filled styrene-butadiene rubber vulcanizates in isooctane found that the diffusivity increased with the concentration of the penetrant. Similarly, Johnson and Thomas [30] in their studies found that $D$ decreased with increase in the level of epoxidation in the rubber system investigated. The particle size of the snail shell powder used in compounding the natural rubber has no clear-cut effect on the $D$ values obtained in the various solvents (Table 2). The table shows that at any particular filler content, solvent, and temperature investigated, the $D$ value may increase or 
TABLE 2: Values of diffusion coefficients $(D)$ for snail shell powder filled natural rubber at different temperatures (filler particle sizes 0.075 and $0.300 \mu \mathrm{m})$.

\begin{tabular}{|c|c|c|c|c|c|c|c|}
\hline \multirow{3}{*}{ Solvent } & \multirow{3}{*}{ Filler content (g) } & \multicolumn{3}{|c|}{$D \times 10^{-5}\left(\mathrm{~cm}^{2} / \mathrm{sec}\right)$} & \multicolumn{3}{|c|}{$D \times 10^{-5}\left(\mathrm{~cm}^{2} / \mathrm{sec}\right)$} \\
\hline & & \multicolumn{3}{|c|}{$0.075 \mu \mathrm{m}$} & \multicolumn{3}{|c|}{$0.300 \mu \mathrm{m}$} \\
\hline & & $313 \mathrm{~K}$ & $333 \mathrm{~K}$ & $353 \mathrm{~K}$ & $313 \mathrm{~K}$ & $333 \mathrm{~K}$ & $353 \mathrm{~K}$ \\
\hline \multirow{5}{*}{ Benzene } & 2 & 4.38 & 3.53 & 3.23 & 4.84 & 3.71 & 3.05 \\
\hline & 5 & 4.07 & 3.90 & 2.97 & 4.67 & 3.67 & 3.26 \\
\hline & 10 & 4.20 & 3.39 & 2.65 & 4.38 & 3.94 & 3.54 \\
\hline & 15 & 4.41 & 4.10 & 2.51 & 5.17 & 3.81 & 2.98 \\
\hline & 20 & 4.38 & 3.33 & 2.57 & 4.07 & 3.47 & 2.86 \\
\hline \multirow{5}{*}{ Toluene } & 2 & 4.47 & 4.39 & 3.47 & 4.94 & 3.89 & 3.34 \\
\hline & 5 & 4.84 & 4.33 & 3.34 & 4.74 & 3.83 & 3.06 \\
\hline & 10 & 4.11 & 3.49 & 3.23 & 4.86 & 3.64 & 3.33 \\
\hline & 15 & 4.47 & 4.17 & 3.41 & 4.41 & 3.80 & 3.24 \\
\hline & 20 & 4.53 & 3.79 & 3.57 & 4.83 & 3.98 & 2.28 \\
\hline \multirow{5}{*}{ Xylene } & 2 & 4.59 & 3.86 & 4.26 & 4.71 & 4.29 & 3.74 \\
\hline & 5 & 4.07 & 3.93 & 4.02 & 4.37 & 4.29 & 3.29 \\
\hline & 10 & 4.37 & 4.24 & 3.87 & 4.70 & 4.29 & 3.38 \\
\hline & 15 & 4.68 & 4.52 & 4.14 & 4.77 & 4.09 & 3.49 \\
\hline & 20 & 4.45 & 4.12 & 3.92 & 4.48 & 4.65 & 3.24 \\
\hline
\end{tabular}

decrease with filler particle size. Since diffusivity depends on the free volume within the polymer and the segmental mobility of polymer chains, the smaller-sized snail shell powderfilled vulcanizate was expected to sorb less solvent than the larger-sized snail shell powder filled rubber vulcanizate, but this was not borne out by the outcome of this study.

4.2. Sorption Coefficient (S). The sorption coefficient $(S)$ was obtained from the plateau regions of the equilibrium sorption curves [33] and is presented in Table 3 for the vulcanizates. The table shows that the sorption coefficient decreased with increase in snail shell powder content in the rubber vulcanizate at any temperature, solvent, and filler particle size considered.

Mathai et al. [32] who studied the transport of substituted benzene through nitrile rubber/natural rubber blend membranes found that the sorption coefficient value decreased with increase in nitrile rubber content. Table 3 also shows that the sorption coefficient was highest in benzene, followed by toluene, and then xylene for any particular temperature and filler particle size considered. This finding contrasts the dependence of $D$ on the solvents used in this study.

It is evident from Table 3 that for the solvents studied, their solubilities in filled natural rubber increased with increase in the sorption temperature from 40 to $80^{\circ} \mathrm{C}$. This result is in agreement with the findings of Michaels et al. [34] who reported that the solubility of solvents in polymers increases with the increase in sorption temperature. Similarly, Johnson and Thomas [30] and Igwe et al. [7] in their sorption studies reported that the sorption coefficient increased with increase in sorption temperature. The sorption coefficient of the rubber vulcanizates is observed to decrease with increase in filler particle size. Sorption is a surface phenomenon, and it is an indication of the tendency of the penetrant to dissolve into the polymer.

4.3. Permeability Coefficient $(P)$. The permeability or permeation coefficient $(P)$ of a penetrant in a polymer membrane depends on the diffusivity as well as solubility or sorption of the penetrant in the polymer membrane. The permeability coefficient $(P)$ of the aromatic solvents in the rubber vulcanizates was obtained using the following expression [35]:

$$
P=D \cdot S
$$

where $D$ is the diffusion coefficient and $S$ is the sorption coefficient.

The values of $P$ are given in Table 4 . The permeability coefficients were generally observed to decrease with increase in sorption temperature for rubber vulcanizates of snail shell powder, particle size: $0.30 \mu \mathrm{m}$.

Generally, higher temperatures will tend to fluidize or make more flexible the polymer chains thereby facilitating the solvent permeability. The permeability coefficient in rubber vulcanizates of snail shell powder, particle size: $0.075 \mu \mathrm{m}$, did not show any definite relationship with the sorption temperature. Johnson and Thomas [30] who studied the transport of $n$-alkanes through epoxidized natural rubber found that the permeability coefficient increased with temperature. Also, Unnikrishnan et al. [36] who investigated the diffusion of aromatic hydrocarbons through filled natural rubber found that the permeability values of NR-penetrant systems followed the same trend as that of diffusivity.

The permeability was, however, found to be independent of the molecular mass, molecular mass volume, density, and dipole moment of the aromatic solvents. This is in contrast to the variation of diffusion coefficient on solvent properties 
TABLE 3: Values of the sorption coefficient $(S)$ for snail shell powder filled natural rubber at different temperatures (filler particle sizes 0.075 and $0.300 \mu \mathrm{m})$.

\begin{tabular}{|c|c|c|c|c|c|c|c|}
\hline \multirow{3}{*}{ Solvents } & \multirow{3}{*}{ Filler contents (g) } & \multicolumn{3}{|c|}{$S(\mathrm{~mol} \%)$} & \multicolumn{3}{|c|}{$S(\mathrm{~mol} \%)$} \\
\hline & & \multicolumn{3}{|c|}{$0.075 \mu \mathrm{m}$} & \multicolumn{3}{|c|}{$0.300 \mu \mathrm{m}$} \\
\hline & & $313 \mathrm{~K}$ & $333 \mathrm{~K}$ & $353 \mathrm{~K}$ & $313 \mathrm{~K}$ & $333 \mathrm{~K}$ & $353 \mathrm{~K}$ \\
\hline \multirow{5}{*}{ Benzene } & 2 & 4.01 & 4.59 & 4.53 & 4.02 & 4.26 & 4.34 \\
\hline & 5 & 4.01 & 4.51 & 4.41 & 4.00 & 4.25 & 4.19 \\
\hline & 10 & 3.76 & 4.10 & 4.07 & 3.91 & 4.26 & 4.12 \\
\hline & 15 & 3.63 & 4.32 & 4.15 & 3.76 & 4.05 & 3.86 \\
\hline & 20 & 3.70 & 3.89 & 3.82 & 3.61 & 3.82 & 3.83 \\
\hline \multirow{5}{*}{ Toluene } & 2 & 3.63 & 3.78 & 4.07 & 3.40 & 3.54 & 3.74 \\
\hline & 5 & 3.43 & 3.61 & 3.84 & 3.31 & 3.52 & 3.71 \\
\hline & 10 & 3.20 & 3.44 & 3.54 & 3.20 & 3.51 & 3.66 \\
\hline & 15 & 3.26 & 3.37 & 3.62 & 3.17 & 3.34 & 3.48 \\
\hline & 20 & 3.07 & 4.14 & 3.51 & 3.11 & 3.29 & 3.35 \\
\hline \multirow{5}{*}{ Xylene } & 2 & 3.37 & 3.43 & 3.50 & 3.08 & 3.23 & 3.31 \\
\hline & 5 & 3.11 & 3.29 & 3.31 & 3.04 & 3.19 & 3.27 \\
\hline & 10 & 2.95 & 3.10 & 3.20 & 3.00 & 3.02 & 3.19 \\
\hline & 15 & 2.90 & 2.99 & 3.11 & 2.89 & 2.96 & 2.99 \\
\hline & 20 & 2.84 & 2.94 & 2.96 & 2.95 & 2.78 & 2.95 \\
\hline
\end{tabular}

TABLE 4: Values of the permeability coefficient $(P)$ for snail shell powder filled natural rubber at different temperatures (filler particles sizes 0.075 and $0.30 \mu \mathrm{m})$.

\begin{tabular}{|c|c|c|c|c|c|c|c|}
\hline \multirow{3}{*}{ Solvent } & \multirow{3}{*}{ Filler content (g) } & \multicolumn{3}{|c|}{$P \times 10^{-5}\left(\mathrm{~cm}^{2} \mathrm{~s}^{-1} \mathrm{~mol} \%\right)$} & \multicolumn{3}{|c|}{$P \times 10^{-5}\left(\mathrm{~cm}^{2} \mathrm{~s}^{-1} \mathrm{~mol} \%\right)$} \\
\hline & & \multicolumn{3}{|c|}{$0.075 \mu \mathrm{m}$} & \multicolumn{3}{|c|}{$0.300 \mu \mathrm{m}$} \\
\hline & & $313 \mathrm{~K}$ & $333 \mathrm{~K}$ & $353 \mathrm{~K}$ & $313 \mathrm{~K}$ & $333 \mathrm{~K}$ & $353 \mathrm{~K}$ \\
\hline \multirow{5}{*}{ Benzene } & 2 & 17.56 & 16.20 & 14.63 & 19.46 & 15.80 & 13.24 \\
\hline & 5 & 16.32 & 17.59 & 13.10 & 18.68 & 15.60 & 13.66 \\
\hline & 10 & 15.79 & 13.90 & 10.79 & 17.13 & 16.78 & 14.58 \\
\hline & 15 & 16.01 & 17.71 & 10.42 & 19.44 & 15.43 & 11.50 \\
\hline & 20 & 16.21 & 12.85 & 9.82 & 14.69 & 13.26 & 10.95 \\
\hline \multirow{5}{*}{ Toluene } & 2 & 16.23 & 16.59 & 14.12 & 16.80 & 13.77 & 12.49 \\
\hline & 5 & 16.60 & 15.63 & 12.83 & 15.63 & 13.48 & 11.35 \\
\hline & 10 & 13.15 & 12.01 & 11.43 & 15.55 & 12.78 & 12.19 \\
\hline & 15 & 14.57 & 14.05 & 12.34 & 13.98 & 12.69 & 11.28 \\
\hline & 20 & 14.52 & 15.59 & 12.53 & 15.02 & 13.09 & 7.28 \\
\hline \multirow{5}{*}{ Xylene } & 2 & 15.47 & 13.24 & 14.91 & 14.51 & 13.86 & 12.58 \\
\hline & 5 & 12.66 & 12.93 & 13.31 & 13.28 & 13.69 & 10.76 \\
\hline & 10 & 12.89 & 13.14 & 12.38 & 14.10 & 12.87 & 10.76 \\
\hline & 15 & 13.57 & 13.51 & 12.88 & 13.79 & 12.11 & 10.44 \\
\hline & 20 & 12.64 & 12.11 & 11.60 & 13.22 & 12.93 & 9.56 \\
\hline
\end{tabular}

obtained in this study. Igwe et al. [7] who studied the uptake of aromatic solvents into polypropylene films found that the permeability increased with increase in dipole movement, molecular mass volume, and molecular mass of the aromatic solvents.

4.4. Activation Energy of Sorption. To obtain the activation energy of sorption of the aromatic solvents in vulcanized natural rubber, the data for the diffusion coefficient $(D)$ were treated with an Arrhenius-type expression [30]:

$$
D=D_{0} \exp \left(\frac{-E_{D}}{R T}\right)
$$

where $E_{D}$ is the activation energy of diffusion, which is a function of the intra- and interchain forces that must be overcome to create the space for a diffusional jump of 
TABLE 5: Values of activation energy $\left(E_{D}\right.$ and $\left.E_{P}\right)$ of snail shell powder filled natural rubber (filler particle size, $0.075 \mu \mathrm{m}$ ).

\begin{tabular}{lccc}
\hline Solvent & Filler content $(\mathrm{g})$ & $E_{D}(\mathrm{KJ} / \mathrm{mol})$ & $E_{P}(\mathrm{KJ} / \mathrm{mol})$ \\
\hline \multirow{3}{*}{ Benzene } & 2 & $-30.60 \times 10^{2}$ & $-18.15 \times 10^{2}$ \\
& 5 & $-30.92 \times 10^{2}$ & $-21.14 \times 10^{2}$ \\
& 10 & $-45.86 \times 10^{2}$ & $-37.69 \times 10^{2}$ \\
& 15 & $-55.29 \times 10^{2}$ & $-41.51 \times 10^{2}$ \\
Toluene & 20 & $-53.16 \times 10^{2}$ & $-49.86 \times 10^{2}$ \\
& 2 & $-24.79 \times 10^{2}$ & $-13.51 \times 10^{2}$ \\
& 5 & $-36.65 \times 10^{2}$ & $-25.39 \times 10^{2}$ \\
& 10 & $-91.59 \times 10^{2}$ & $-14.05 \times 10^{2}$ \\
& 15 & $-26.69 \times 10^{2}$ & $-16.37 \times 10^{2}$ \\
Xylene & 20 & $-23.96 \times 10^{2}$ & $-14.07 \times 10^{2}$ \\
& 2 & $-7.98 \times 10^{2}$ & $-4.22 \times 10^{2}$ \\
& 5 & $-1.35 \times 10^{2}$ & $-4.98 \times 10^{2}$ \\
& 10 & $-11.99 \times 10^{2}$ & $-3.88 \times 10^{2}$ \\
& 15 & $-12.09 \times 10^{2}$ & $-5.12 \times 10^{2}$ \\
& 20 & $-12.69 \times 10^{2}$ & $-8.53 \times 10^{2}$ \\
\hline
\end{tabular}

TABLe 6: Values of activation energy $\left(E_{D}\right.$ and $\left.E_{P}\right)$ of snail shell powder filled natural rubber (filler particle size, $0.300 \mu \mathrm{m}$ ).

\begin{tabular}{lccc}
\hline Solvent & Filler content $(\mathrm{g})$ & $E_{D}(\mathrm{KJ} / \mathrm{mol})$ & $E_{P}(\mathrm{KJ} / \mathrm{mol})$ \\
\hline \multirow{3}{*}{ Benzene } & 2 & $-46.13 \times 10^{2}$ & $-38.42 \times 10^{2}$ \\
& 5 & $-36.05 \times 10^{2}$ & $-31.23 \times 10^{2}$ \\
& 10 & $-21.22 \times 10^{2}$ & $-15.82 \times 10^{2}$ \\
& 15 & $-55.01 \times 10^{2}$ & $-52.17 \times 10^{2}$ \\
Toluene & 20 & $-35.07 \times 10^{2}$ & $-29.09 \times 10^{2}$ \\
& 2 & $-39.17 \times 10^{2}$ & $-29.73 \times 10^{2}$ \\
& 10 & $-43.58 \times 10^{2}$ & $-32.21 \times 10^{2}$ \\
& 15 & $-38.07 \times 10^{2}$ & $-24.55 \times 10^{2}$ \\
Xylene & 20 & $-30.69 \times 10^{2}$ & $-21.34 \times 10^{2}$ \\
& 2 & $-74.05 \times 10^{2}$ & $-71.26 \times 10^{2}$ \\
\hline & 10 & $-22.87 \times 10^{2}$ & $-15.69 \times 10^{2}$ \\
& 15 & $-27.78 \times 10^{2}$ & $-20.42 \times 10^{2}$ \\
& 20 & $-32.58 \times 10^{2}$ & $-26.57 \times 10^{2}$ \\
& 5 & $-31.12 \times 10^{2}$ & $-20.14 \times 10^{2}$ \\
& 10 & $-30.83 \times 10^{2}$ & $-58.32 \times 10^{2}$ \\
\hline
\end{tabular}

the penetrant molecule, $D_{0}$ is a pre-exponential factor, and $R T$ has the conventional usual meaning. Plots of $\log D$ against $1 / T$ for the aromatic solvents were made, and the calculated activation energies of diffusion $\left(E_{D}\right)$ are shown in Tables 5 and 6. $E_{D}$ values were all negative. Generally, the activation energy of diffusion $\left(E_{D}\right)$ will be greater, the larger the size of the solvent molecule and vice versa. For rubber vulcanizates of snail shell powder, particle size, $0.075 \mu \mathrm{m}$, the $E_{D}$ was highest in xylene as expected for all the snail shell powder contents investigated. However, for rubber vulcanizates of snail shell powder, particle size $0.30 \mu \mathrm{m}, E_{D}$ was highest in xylene for the following snail shell powder contents: 2 , 5 , and $20 \mathrm{~g}$. No definite order in the variation of $E_{D}$ with the solvents studied or snail shell powder contents investigated was observed in this study. Johnson and Thomas [30] who investigated the effect of epoxidation on the transport behaviour of natural rubber found that the activation energy of diffusion increased with increase in the size of the penetrants. From Tables 5 and 6, it is evident that the particle size of the snail shell powder used in compounding the natural rubber vulcanizates influenced the $E_{D}$ obtained in the various solvents used in this study. The tables equally showed that as the particle size of snail shell powder increased, the $E_{D}$ values generally increased in xylene, and toluene. The later observation was also noted in the solvent benzene at snail shell powder contents, 2 and $5 \mathrm{~g}$ only. Thus, the activation energy of diffusion into snail shell powder filled natural rubber may depend to a large extent on the snail shell powder particle size.

4.5. Enthalpy of Absorption $\left(\Delta H_{s}\right)$ and Entropy of Absorption $\left(\Delta S_{s}\right)$. In order to determine $\Delta H_{s}$ and $\Delta S_{s}$ for the solvents in the vulcanized natural rubber, the equilibrium absorption constant $\left(K_{s}\right)$ of the solvents was first determined using the following formula [36]:

$K_{s}$

Number of moles of the solvent absorbed at equilibrium Mass of the natural rubber vulcanizate

The data obtained were used in calculating the enthalpy of absorption $\left(\Delta H_{s}\right)$ and entropy of absorption $\left(\Delta S_{s}\right)$ in natural rubber vulcanizates. The values of $K_{s}$ were substituted into Van't Hoff's equation [30]:

$$
\log K_{s}=\frac{\Delta S_{s}}{2.303 R}-\frac{\Delta H_{s}}{2.303 R T},
$$

and plots of Van't hoff's equations made were used in calculating $\Delta H_{s}$ and $\Delta S_{s}$. The values of $\Delta H_{s}$ and $\Delta S_{s}$ obtained are given in Tables 7 and 8 . For rubber vulcanizates of snail shell powder $(0.075 \mu \mathrm{m})$, the calculated $\Delta H_{s}$ is generally positive and showed no relationship to the penetrant (solvent) size, the dipole moment, filler content, or filler particle size. $\Delta H_{s}$ is a composite parameter involving contributions from (1) Henry's law, which is needed for the formation of a site and the dissolution of the species into that site (the formation of the site involves an endodermic contribution), and (2) Langmuir's (hole-filling) sorption mechanism, in which case, the site already exists in the polymer matrix and sorption by hole filling gives exothermic heat of sorption.

In this study, the positive $\Delta H_{s}$ values obtained for the aromatic solvents suggest that sorption in this case is dominated by Henry's mode with endodermic contributions. Unnikrishnan and Thomas [16] in their study found that the $\Delta H_{s}$ obtained were negative in all cases, and increased regularly from benzene to mesitylene for a given sample. This trend could indicate an increased exothermicity of the sorption process with increase in molecular size of solvents.

The calculated $\Delta S_{s}$ for the solvents were all positive, and did not show any relationship to the snail shell powder content, particle size, penetrant (solvent) size, or solvent dipole moment. 
TABLE 7: Values of enthalpy of absorption $\left(\Delta H_{s}\right)$, entropy of absorption $\left(\Delta S_{s}\right)$, and Gibbs free energy $\left(\Delta G_{s}\right)$ of snail shell powder filled natural rubber (filler particle size, $0.075 \mu \mathrm{m}$ ).

\begin{tabular}{|c|c|c|c|c|}
\hline Solvent & Fillercontent $(\mathrm{g})$ & $\Delta H_{s}(\mathrm{KJ} / \mathrm{mol})$ & $\Delta S_{s}(\mathrm{~J} / \mathrm{mol})$ & $\Delta G_{s}(\mathrm{KJ} / \mathrm{mol})$ \\
\hline \multirow{5}{*}{ Benzene } & 2 & $28.74 \times 10^{2}$ & 18.85 & $28.68 \times 10^{2}$ \\
\hline & 5 & $22.42 \times 10^{2}$ & 16.81 & $22.37 \times 10^{2}$ \\
\hline & 10 & $18.93 \times 10^{2}$ & 15.11 & $18.89 \times 10^{2}$ \\
\hline & 15 & $32.83 \times 10^{2}$ & 19.08 & $31.74 \times 10^{2}$ \\
\hline & 20 & $7.81 \times 10^{2}$ & 11.37 & $7.77 \times 10^{2}$ \\
\hline \multirow{5}{*}{ Toluene } & 2 & $26.42 \times 10^{2}$ & 18.41 & $26.36 \times 10^{2}$ \\
\hline & 5 & $25.72 \times 10^{2}$ & 17.75 & $25.67 \times 10^{2}$ \\
\hline & 10 & $23.05 \times 10^{2}$ & 16.34 & $23.00 \times 10^{2}$ \\
\hline & 15 & $24.05 \times 10^{2}$ & 16.80 & $24.00 \times 10^{2}$ \\
\hline & 20 & $32.83 \times 10^{2}$ & 19.72 & $32.77 \times 10^{2}$ \\
\hline \multirow{5}{*}{ Xylene } & 2 & $8.77 \times 10^{2}$ & 13.38 & $8.73 \times 10^{2}$ \\
\hline & 5 & $14.48 \times 10^{2}$ & 14.61 & $14.44 \times 10^{2}$ \\
\hline & 10 & $18.09 \times 10^{2}$ & 15.20 & $18.05 \times 10^{2}$ \\
\hline & 15 & $5.57 \times 10^{2}$ & 11.54 & $5.53 \times 10^{2}$ \\
\hline & 20 & $9.82 \times 10^{2}$ & 12.33 & $9.78 \times 10^{2}$ \\
\hline
\end{tabular}

TABLE 8: Values of enthalpy of absorption $\left(\Delta H_{s}\right)$, entropy of absorption $\left(\Delta S_{s}\right)$, and Gibbs free energy $\left(\Delta G_{s}\right)$ of snail shell powder filled natural rubber (filler particle size, $0.300 \mu \mathrm{m}$ ).

\begin{tabular}{|c|c|c|c|c|}
\hline Solvent & Filler content $(\mathrm{g})$ & $\Delta H_{s}(\mathrm{KJ} / \mathrm{mol})$ & $\Delta S_{s}(\mathrm{~J} / \mathrm{mol})$ & $\Delta G_{s}(\mathrm{KJ} / \mathrm{mol})$ \\
\hline \multirow{5}{*}{ Benzene } & 2 & $18.04 \times 10^{2}$ & 15.31 & $17.99 \times 10^{2}$ \\
\hline & 5 & $10.71 \times 10^{2}$ & 12.98 & $10.67 \times 10^{2}$ \\
\hline & 10 & $12.71 \times 10^{2}$ & 13.49 & $12.67 \times 10^{2}$ \\
\hline & 15 & $6.81 \times 10^{2}$ & 11.27 & $6.77 \times 10^{2}$ \\
\hline & 20 & $14.09 \times 10^{2}$ & 13.17 & $14.05 \times 10^{2}$ \\
\hline \multirow{5}{*}{ Toluene } & 2 & $21.48 \times 10^{2}$ & 16.32 & $21.43 \times 10^{2}$ \\
\hline & 5 & $26.08 \times 10^{2}$ & 17.59 & $26.03 \times 10^{2}$ \\
\hline & 10 & $30.87 \times 10^{2}$ & 18.90 & $30.81 \times 10^{2}$ \\
\hline & 15 & $21.49 \times 10^{2}$ & 15.77 & $21.44 \times 10^{2}$ \\
\hline & 20 & $17.12 \times 10^{2}$ & 14.26 & $17.08 \times 10^{2}$ \\
\hline \multirow{5}{*}{ Xylene } & 2 & $16.63 \times 10^{2}$ & 15.17 & $16.59 \times 10^{2}$ \\
\hline & 5 & $16.87 \times 10^{2}$ & 15.14 & $16.82 \times 10^{2}$ \\
\hline & 10 & $13.98 \times 10^{2}$ & 14.01 & $13.94 \times 10^{2}$ \\
\hline & 16 & $7.88 \times 10^{2}$ & 11.83 & $7.84 \times 10^{2}$ \\
\hline & 20 & $15.41 \times 10^{2}$ & 13.76 & $15.36 \times 10^{2}$ \\
\hline
\end{tabular}

4.6. Gibbs Free Energy of Sorption $\left(\Delta G_{s}\right)$. The change in $\Delta G_{s}$ for the aromatic solvents in filled natural rubber was obtained using the following expression:

$$
\Delta G_{s}=\Delta H_{s}-T \Delta S_{s},
$$

where $T$ is the temperature in Kelvin. The values of $\Delta H_{s}$ and $\Delta S_{s}$ earlier determined for the solvents were substituted into (7), and the calculated values of $\Delta G_{s}$ are also shown in Tables 7 and 8 for the solvents benzene, toluene, and xylene. The calculated $\Delta G_{s}$ values were all positive, and this was an indication of the nonspontaneity of the solubility of filled natural rubber in the aromatic solvents at $313 \mathrm{~K}$. The calculated $\Delta G_{s}$ did not show any reasonable relationship to the snail shell powder content, particle size, solvent size, or dipole moment of solvent.
Igwe [8] who studied the uptake of aromatic solvents (benzene, toluene, and xylene) by polyethylene films found that the solvents showed similar $\Delta G_{s}$ values, which indicated that the change in $\Delta G_{s}$ of the aromatic solvents in polyethylene films might be independent of the solvent properties.

4.7. Transport Mechanism. The mechanism of diffusion of the aromatic solvents into filled natural rubber was analysed using the following empirical relation [37]:

$$
\log \frac{Q_{t}}{Q_{\infty}}=\log k+n \log t
$$

where $Q_{t}$ and $Q_{\infty}$ are the mol \% sorption at time $t$ and equilibrium, respectively. $k$ is a constant that depends on the structural characteristics of the rubber and gives information 
TABLE 9: Values of $n$ and $k$ for snail shell powder filled natural rubber at different temperatures (filler particle size, $0.075 \mu \mathrm{m}$ ).

\begin{tabular}{|c|c|c|c|c|c|c|c|}
\hline \multirow{2}{*}{ Solvent } & \multirow{2}{*}{ Filler content (g) } & \multicolumn{3}{|c|}{$n$} & \multicolumn{3}{|c|}{$k$} \\
\hline & & $313 \mathrm{~K}$ & $333 \mathrm{~K}$ & $353 \mathrm{~K}$ & $40^{\circ} \mathrm{C}$ & $60^{\circ} \mathrm{C}$ & $80^{\circ} \mathrm{C}$ \\
\hline \multirow{5}{*}{ Benzene } & 2 & 0.42 & 0.31 & 0.32 & 0.11 & 0.18 & 0.18 \\
\hline & 5 & 0.35 & 0.38 & 0.32 & 0.15 & 0.16 & 0.18 \\
\hline & 10 & 0.36 & 0.37 & 0.28 & 0.13 & 0.14 & 0.20 \\
\hline & 15 & 0.33 & 0.39 & 0.27 & 0.16 & 0.18 & 0.23 \\
\hline & 20 & 0.36 & 0.31 & 0.30 & 0.14 & 0.18 & 0.21 \\
\hline \multirow{5}{*}{ Toluene } & 2 & 0.40 & 0.38 & 0.32 & 0.10 & 0.12 & 0.17 \\
\hline & 5 & 0.37 & 0.38 & 0.31 & 0.12 & 0.12 & 0.18 \\
\hline & 10 & 0.34 & 0.33 & 0.33 & 0.15 & 0.16 & 0.17 \\
\hline & 15 & 0.36 & 0.34 & 0.34 & 0.13 & 0.15 & 0.17 \\
\hline & 20 & 0.35 & 0.35 & 0.35 & 0.14 & 0.14 & 0.15 \\
\hline \multirow{5}{*}{ Xylene } & 2 & 0.37 & 0.36 & 0.40 & 0.12 & 0.14 & 0.16 \\
\hline & 5 & 0.33 & 0.35 & 0.38 & 0.13 & 0.14 & 0.16 \\
\hline & 10 & 0.36 & 0.37 & 0.37 & 0.13 & 0.15 & 0.18 \\
\hline & 15 & 0.17 & 0.40 & 0.38 & 0.14 & 0.14 & 0.17 \\
\hline & 20 & 0.33 & 0.39 & 0.35 & 0.11 & 0.12 & 0.14 \\
\hline
\end{tabular}

TABLE 10: Values of $n$ and $k$ of snail shell powder filled natural rubber at different temperatures (filler particle size, $0.300 \mu \mathrm{m}$ ).

\begin{tabular}{|c|c|c|c|c|c|c|c|}
\hline \multirow{2}{*}{ Solvent } & \multirow{2}{*}{ Filler content (g) } & \multicolumn{3}{|c|}{$n$} & \multicolumn{3}{|c|}{$k$} \\
\hline & & $313 \mathrm{~K}$ & $333 \mathrm{~K}$ & $353 \mathrm{~K}$ & $313 \mathrm{~K}$ & $333 \mathrm{~K}$ & $353 \mathrm{~K}$ \\
\hline \multirow{5}{*}{ Benzene } & 2 & 0.39 & 0.36 & 0.30 & 0.11 & 0.14 & 0.20 \\
\hline & 5 & 0.39 & 0.34 & 0.35 & 0.11 & 0.15 & 0.16 \\
\hline & 10 & 0.36 & 0.36 & 0.29 & 0.13 & 0.14 & 0.17 \\
\hline & 15 & 0.43 & 0.35 & 0.37 & 0.10 & 0.14 & 0.16 \\
\hline & 20 & 0.36 & 0.36 & 0.34 & 0.14 & 0.14 & 0.17 \\
\hline \multirow{5}{*}{ Toluene } & 2 & 0.40 & 0.35 & 0.33 & 0.10 & 0.13 & 0.16 \\
\hline & 5 & 0.38 & 0.39 & 0.30 & 0.12 & 0.13 & 0.20 \\
\hline & 10 & 0.39 & 0.37 & 0.32 & 0.11 & 0.14 & 0.17 \\
\hline & 15 & 0.33 & 0.36 & 0.34 & 0.14 & 0.14 & 0.16 \\
\hline & 20 & 0.36 & 0.35 & 0.30 & 0.13 & 0.15 & 0.20 \\
\hline \multirow{5}{*}{ Xylene } & 2 & 0.39 & 0.42 & 0.36 & 0.10 & 0.10 & 0.14 \\
\hline & 5 & 0.37 & 0.40 & 0.33 & 0.13 & 0.14 & 0.16 \\
\hline & 10 & 0.42 & 0.38 & 0.35 & 0.10 & 0.12 & 0.15 \\
\hline & 15 & 0.39 & 0.36 & 0.35 & 0.11 & 0.13 & 0.16 \\
\hline & 20 & 0.38 & 0.38 & 0.34 & 0.11 & 0.12 & 0.16 \\
\hline
\end{tabular}

about the interaction between the rubber and solvents. The value of $n=0.5$ indicates a Fickian mode of transport while $n=1$ indicates case II transport. The value of $n$ between 0.5 and 1 indicates anomalous transport behaviour. The values of $n$ and $k$ for the rubber vulcanizates were obtained by regression analysis of $\log \left(Q_{t} / Q_{\infty}\right)$ versus $\log t$, and the results are given in Tables 9 and 10. From Tables 9 and 10, it can be seen that the values of $n$ obtained for the rubber vulcanizates at different temperatures, and snail shell powder particle sizes are Fickian. The values of $n$ did not show any relationship to the amount of snail shell powder incorporated into the natural rubber.

Mathew et al. [28] who studied the transport of substituted benzene through natural rubber/polystyrene (NR/PS) interpenetrating polymer network membranes found the mode of transport to be anomalous. For the prepared rubber vul- canizates of snail shell powder, the values of $k$ were observed to increase with increase in sorption temperature for the solvents studied. The values of $k$ obtained in this study did not show any relationship to snail shell powder content or solvent employed. The similarity in the values of $k$ obtained in the various solvents for the natural rubber vulcanizates study may be an indication of the similarity of interaction between the rubber vulcanizates and aromatic solvents employed in this study. Kumnuantip and Sombatsompop [35] in their studies reported a general increase of $k$ with increase in reclaimed natural rubber.

\section{Conclusions}

The transport of three aromatic solvents (benzene, toluene, and xylene) through snail shell powder filled natural rubber 
has been studied. The molar percentage solvent uptake $\left(\% Q_{t}\right)$ in the filled natural rubber was found to show initial increases in the mass of the solvents sorbed, until the maximum absorption was reached, at which time, the mass of the absorbed solvent remained constant. The diffusion and sorption coefficients obtained for the aromatic solvents in snail shell powder filled natural rubber increased with increase in the sorption temperature. The permeability coefficients $(P)$ for the solvents were found to decrease with increase in the sorption temperature for rubber vulcanizates of snail shell powder, particle size: $0.300 \mu \mathrm{m}$. The rubber vulcanizates of snail shell powder, particle size: $0.075 \mu \mathrm{m}$, did not show any relationship with the sorption temperature. The calculated enthalpies of sorption $\left(\Delta H_{s}\right)$, entropies of sorption $\left(\Delta S_{s}\right)$, and Gibbs free energies of sorption $\left(\Delta G_{s}\right)$ were all positive while the Arrhenius activation energies $\left(E_{D}\right)$ were all negative. The positive $\Delta G_{s}$ obtained in this study is an indication of nonspontaneity of the solubility of snail shell powder filled natural rubber in the aromatic solvents at $313 \mathrm{~K}$. The mode of transport of the aromatic solvents into filled natural rubber has been found to be Fickian. The transport parameters presented in this study have not only provided additional characterization of the snail shell powder filled natural rubber but gave an insight into the behaviour of snail shell powder filled natural rubber in external liquid environment which is essential for their successful applications. The data obtained could be of importance in problem solving like designing a barrier material or tubes for transporting liquids.

\section{References}

[1] Y. M. Lee, D. Bourgeois, and G. Belfort, "Sorption, diffusion, and pervaporation of organics in polymer membranes," Journal of Membrane Science, vol. 44, no. 2-3, pp. 161-181, 1989.

[2] T. M. Aminabhavi and U. S. Aithal, "Molecular transport of oxygen and nitrogen through polymer films," Journal of Macromolecular Science Part C, vol. 31, no. 2-3, pp. 117-163, 1991.

[3] W. J. Koros, "Barrier polymers and structures; overview," in Barrier Polymers and Structures, W. J. Koros, Ed., vol. 423 of ACS Symposium Series, chapter 1, pp. 1-21, American Chemical Society, Washington, DC, USA, 1990.

[4] S. V. Dixon-Garrett, K. Nagai, and B. D. Freeman, "Sorption, diffusion, and permeation of ethylbenzene in poly(1-trimethylsilyl-1-propyne)," Journal of Polymer Science Part B, vol. 38, no. 8, pp. 1078-1089, 2000.

[5] M. V. Sefton and J. L. Mann, "Absorption of benzene by opencell polyurethane foams," Journal of Applied Polymer Science, vol. 25, no. 5, pp. 829-839, 1980.

[6] N. S. Schneider, J. L. Illinger, and M. A. Cleaves, "Liquid sorption in a segmented polyurethane elastomer," Polymer Engineering and Science, vol. 26, no. 22, pp. 1547-1551, 1986.

[7] I. O. Igwe, C. M. Ewulonu, and I. Igboanugo, "Studies on the diffusion characteristics of some aromatic solvents into polypropylene film," Journal of Applied Polymer Science, vol. 102, no. 2, pp. 1985-1989, 2006.

[8] I. O. Igwe, "Uptake of aromatic solvents by polyethylene films," Journal of Applied Polymer Science, vol. 104, no. 6, pp. 38493854, 2007.
[9] M. D. Cates and J. H. White Jr., "Preparation and properties of fibers containing mixed polymers. I. Polyacrylonitrile-cellulose acetate fibers," Journal of Polymer Science, vol. 20, no. 94, pp. 155-180, 1956.

[10] M. D. Cates and J. H. White Jr., "Preparation and properties of fibres containing mixed polymers. II. Polyacrylonitrile-silk fibres," Journal of Polymer Science, vol. 21, pp. 181-195, 1956.

[11] M. D. Cates and J. H. White Jr., "Preparation and properties of fibers containing mixed polymers. III. Polyacrylonitrile-silk fibers," Journal of Polymer Science, vol. 21, no. 97, pp. 125-138, 1956.

[12] S. U. Hong and J. L. Duda, "Penetrant transport in polyethylene-polystyrene semi-interpenetrating polymer networks," Journal of Applied Polymer Science, vol. 65, no. 1, pp. 51-57, 1997.

[13] H. C. Obasi, O. Ogbobe, and I. O. Igwe, "Diffusion characteristics of toluene into natural rubber/linear low density polyethylene blends," International Journal of Polymer Science, vol. 2009, Article ID 140682, 6 pages, 2009.

[14] T. M. Aminabhavi, U. S. Aithal, and S. S. Shukla, "Molecular transport of organic liquids through polymer films," Journal of Macromolecular Science, vol. 29, no. 2-3, pp. 319-363, 1989.

[15] E. Sada, H. Kumazawa, P. Xu, and S. T. Wang, "Permeation of mixed gases in glassy polymer membranes," Journal of Applied Polymer Science, vol. 40, no. 7-8, pp. 1391-1399, 1990.

[16] G. Unnikrishnan and S. Thomas, "Interaction of crosslinked natural rubber with chlorinated hydrocarbons," Polymer, vol. 39, no. 17, pp. 3933-3938, 1998.

[17] M. J. Smith and N. A. Peppas, "Effect of the degree of crosslinking on penetrant transport in polystyrene," Polymer, vol. 26, no. 4, pp. 569-574, 1985.

[18] G. J. Kraus, "Swelling of filler-reinforced vulcanizates," Journal of Applied Polymer Science, vol. 7, no. 3, pp. 861-871, 1963.

[19] R. M. Barrer, J. A. Barrie, and M. G. Rogers, "Heterogeneous membranes diffusion in filled rubber," Journal of Polymer Science Part A, vol. 1, no. 8, pp. 2565-2586, 1963.

[20] F. de Candia, L. Gargani, and A. Renzulli, "Transport properties of filled elastomeric networks," Journal of Applied Polymer Science, vol. 41, no. 5-6, pp. 955-964, 1990.

[21] S. N. Lawandy and S. H. Botros, "Effect of type and amount of carbon black on the interaction between polychloroprene rubber and motor oil," Journal of Applied Polymer Science, vol. 42, no. 1, pp. 137-141, 1991.

[22] T. K. Kwei and C. A. Kunins, "Polymer filler interaction: vapour sorption studies," Journal of Applied Polymer Science, vol. 8, pp. 1483-1490, 1964.

[23] B. B. S. T. Boonstra and E. M. Dannenberg, "The equilibrium swelling data of filled natural rubber," Rubber Age, vol. 1, pp. 825-838, 1958.

[24] P. B. Stickney and W. Mueller, "The kinetics of swelling of carbon black filled styrene butadiene rubber vulcanizates in iso-octane," Rubber Chemistry and Technology, vol. 42, pp. 604-611, 1969.

[25] S. N. Lawandy and F. H. Helaly, "Diffusion of a volatile liquid in polychloroprene rubber," Journal of Applied Polymer Science, vol. 32, no. 6, pp. 5279-5286, 1989.

[26] A. Ahmad, D. H. Mohd, and I. Abdullah, "Mechanical properties of filled natural rubber/linear low density polyethylene blends," Iranian Polymer Journal, vol. 13, no. 3, pp. 173-178, 2004.

[27] I. O. Igwe and A. M. Ejim, "The effects of incorporating snail shell powder as filler on the properties of natural rubber," Material Science and Application, vol. 2, pp. 801-809, 2011. 
[28] A. P. Mathew, S. Packirisamy, M. G. Kumaran, and S. Thomas, "Transport of styrene monomer through vulcanized natural rubber," Polymer, vol. 25, no. 35, pp. 4935-4942, 2002.

[29] A. B. Desai and G. L. Wilkes, "Solvent-induced crystallization of polyethylene terephthalate," Journal of Polymer Science, no. 46, pp. 291-319, 1974.

[30] T. Johnson and S. Thomas, "Effect of epoxidation on the transport behaviour and mechanical properties of natural rubber," Polymer, vol. 41, no. 20, pp. 7511-7522, 2000.

[31] H. Ismail and S. Suzaimah, "Styrene butadiene rubber/epoxidized natural rubber blends: dynamic properties, curing characteristics and swelling studies," Polymer Testing, vol. 19, no. 8, pp. 879-888, 2000.

[32] A. E. Mathai, R. P. Singh, and S. Thomas, "Transport of substituted benzenes through nitrile rubber/natural rubber blend membranes," Journal of Membrane Science, vol. 202, pp. 35-54, 2002.

[33] T. M. Aminabhavi and H. T. S. Phayde, "Molecular transport of alkanes through thermoplastic miscible blends of ethylenepropylene random copolymer and isostatic polypropylene," Journal of Applied Polymer Science, vol. 55, pp. 1335-1352, 1995.

[34] A. S. Michaels, W. Vieth, A. S. Hoffman, and H. A. Alcalay, "Structure-property relationships for liquid transport in modified polypropylene," Journal of Applied Polymer Science, vol. 13, pp. 577-598, 1969.

[35] C. Kumnuantip and N. Sombatsompop, "Dynamic mechanical properties and swelling behaviour of NR/reclaimed rubber blends," Materials Letters, vol. 57, no. 21, pp. 3167-3174, 2003.

[36] G. Unnikrishnan, S. Thomas, and S. Varghese, "Sorption and diffusion of aromatic hydrocarbons through filled natural rubber," Polymer, vol. 37, no. 13, pp. 2687-2693, 1996.

[37] L. M. Lucht and N. A. Peppas, "Transport of penetrants in the macromolecular structure of coals. V. Anomalous transport in pre-treated coal particles," Journal of Applied Polymer Science, vol. 33, no. 5, pp. 1557-1566, 1987. 

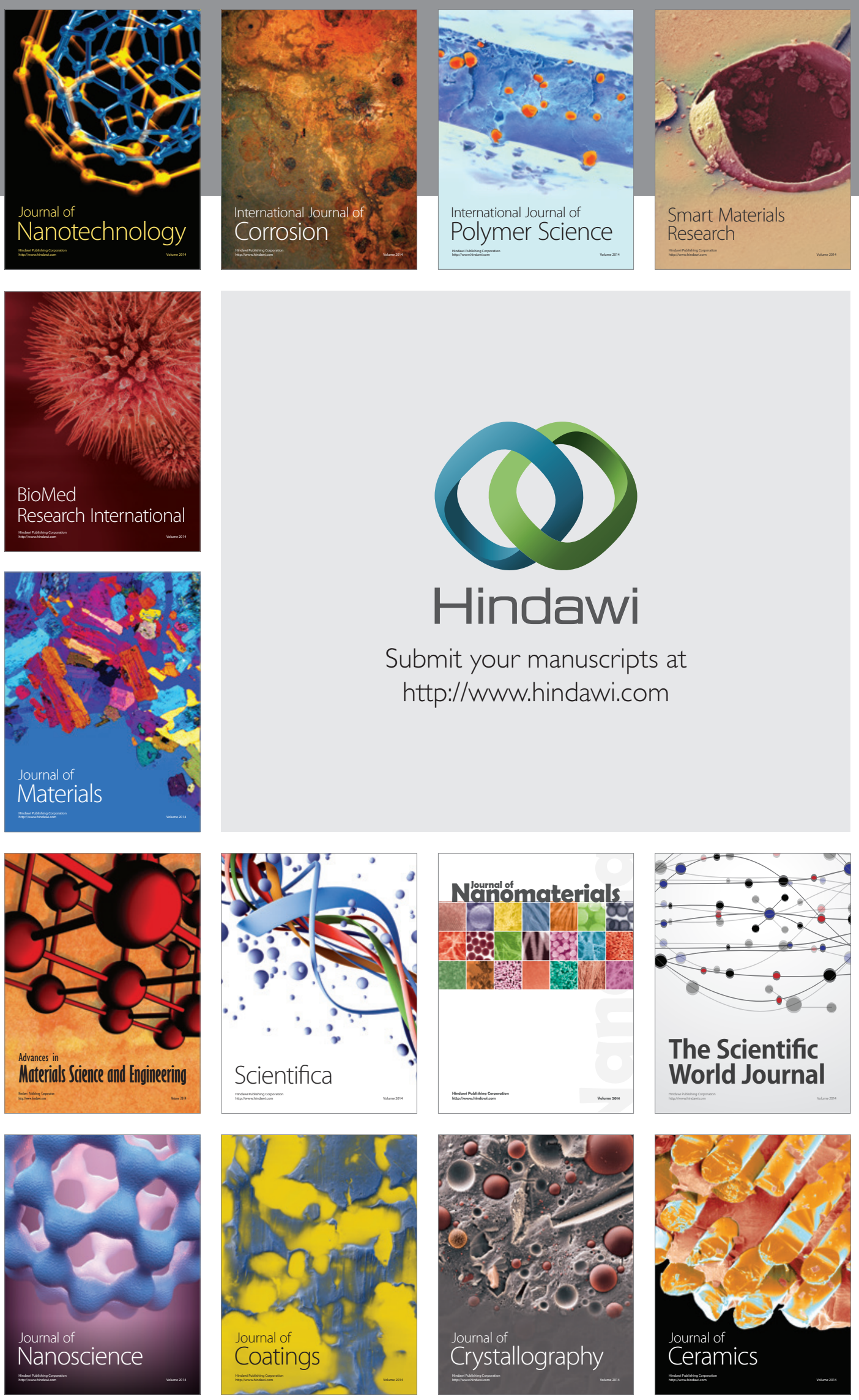

The Scientific World Journal

Submit your manuscripts at

http://www.hindawi.com

\section{World Journal}

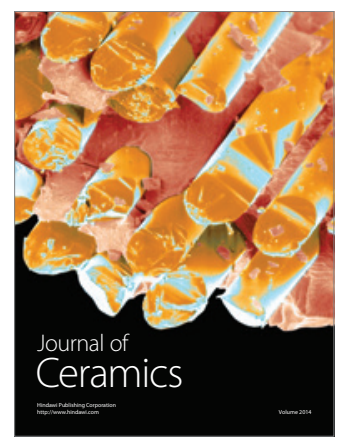

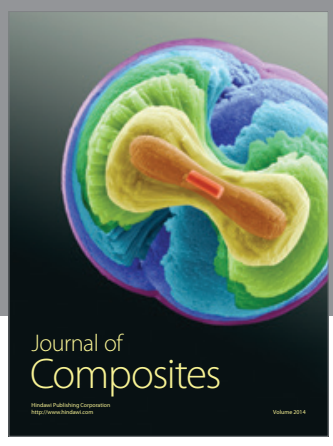
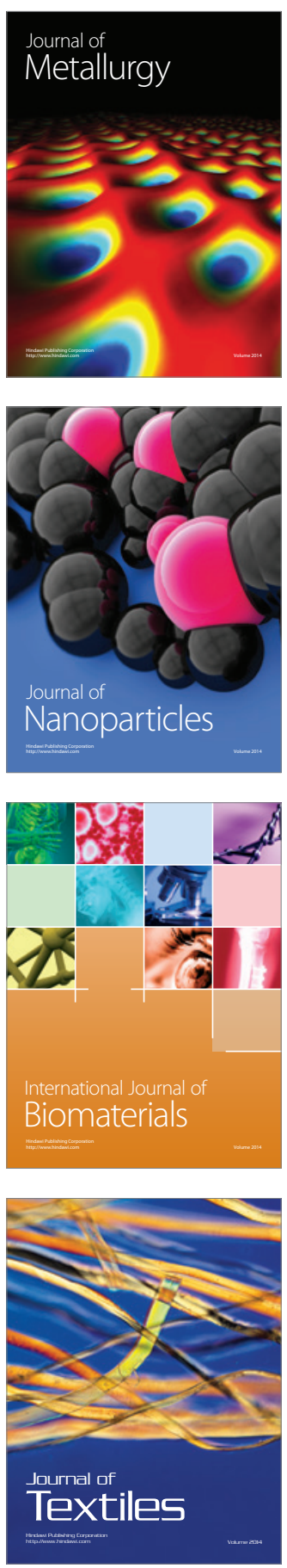